\title{
Evans Staging System
}

National Cancer Institute

\section{Source}

National Cancer Institute. Evans Staging System. NCI Thesaurus. Code C85407.

A staging system for neuroblastoma proposed by Evans, based on both the site of orig in and the clinical behavior of the tumor. 